\title{
Üniversite Öğrencilerinin Stres Durumları ile Fruktoz ve İşlenmiş Besin Tüketimi Arasındaki İlişki
}

\author{
M. Merve TENGILIMMOĞLU METİN ${ }^{1}$, Ebru MELEKOĞLU ${ }^{1,2 *}$
}

\begin{abstract}
ÖZ
Bu çalışmaya, lisans öğrenimine devam eden 225 öğrenci (132 kadın ve 93 erkek) katılmıştır. Veriler; sosyodemografik bilgi, işlenmiş besin tüketim sıklığı, fruktoz tüketim sıklı̆̆ı, algılanan stres ölçeği olmak üzere dört bölümden oluşan anket kullanılarak sınav dönemi ve sınav olmayan dönem olmak üzere iki kez toplanmıştır. Sınav döneminde hem kız hem erkek öğrencilerde işlenmiş besin tüketimleri anlamlı artış göstermiştir $(\mathrm{p}<0.05)$. Benzer şekilde sınav döneminde her iki cinsiyette günlük fruktoz ve şeker tüketimleri ile şeker eklenmiş hazır yiyecek ve içecek tüketimleri anlamlı artış göstermiştir $(\mathrm{p}<0.05)$. Bu sonuçlar, akademik stresin hem erkek hem de kız öğrencilerde sağlıksız besin seçimine neden olabileceğini ortaya koymaktadır.
\end{abstract}

Anahtar Kelimeler: Fruktoz, işlenmiş besin, algılanan stres, besin seçimi

\section{The Relationship Between Stress Status and Consumption of Fructose and Processed Food in University Students}

\begin{abstract}
In this study, 225 (132 females and 93 males) students who continue their undergraduate education were included in this study. The data were collected twice (an examination and a non-examination period) using sociodemographic information consisting of five sections: processed and fructose consumption frequency, perceived stress scale. The consumption of processed food increased significantly $(p<0.05)$ in both female and male participants during the examination period. Similarly, daily fructose, sugar and sugar-added ready-to-drink food and beverage consumption increased significantly in both genders during the examination period $(\mathrm{p}<0.05)$. These results reveal that academic stress may cause unhealthy food choices in students.
\end{abstract}

Keywords: Fructose, processed food, perceived stress, food choice

ORCID ID (Yazar sirasına göre)

0000-0003-0363-5645, 0000-0002-2342-221X

Yayın Kuruluna Geliş Tarihi: 21.10.2021

Kabul Tarihi: 27.12.2021

${ }^{1}$ Hacettepe Üniversitesi, Sağlık Bilimleri Fakültesi, Beslenme ve Diyetetik Bölümü, Ankara

${ }^{2}$ Çukurova Üniversitesi, Sağlık Bilimleri Fakültesi, Beslenme ve Diyetetik Bölümü, Adana

*Eposta: ebrumelekoglu@ hotmail.com 


\section{Üniversite Öğrencilerinin Stres Durumları ile Fruktoz ve İşlenmiş Besin Tüketimi Arasındaki İlişki}

\section{Giriş}

Stresin bir bireyin sağlığını sadece doğrudan fizyolojik süreçler yoluyla değil, aynı zamanda sağlığı etkileyen davranışları değiştirerek de etkileyebileceğine dair önemli kanıtlar vardır. Beslenme ve besin seçimi de bu sağlık davranışlarından biridir (Unusan, 2006). Stresin tüketilen yiyecek miktarını etkilediği gösterilmiştir. Bazı çalışmalar, bireylerin stresli hissettiklerinde yüksek kalorili ve yüksek yağlı besin tüketimini artırma eğiliminde olduklarını gösterirken, diğer çalışmalar bireylerin stres altındayken besin tüketimlerinin azaldığını bildirmiştir (Unusan, 2006; Zellner ve ark., 2006). Stresin sadece tüketilen besin miktarını değil aynı zamanda besin seçimi ile de ilişkili olduğunu gösteren çalıșmalar stresli zamanlarda karbonhidrat içeriği yüksek besinlerin tercih edildiğini bildirmektedir (Cartwright ve ark., 2003). Bu artış kısmen karbonhidrat alımı ile serotonin beyin aktivitesi arasındaki ilişkiye atfedilmiştir. Serotonin, merkezi sinir sisteminde anksiyete, depresyon ve öfke gibi ruh hallerini ve davranışları değiştirme kapasitesine sahip bir nörotransmitterdir. (Papier, Ahmed, Lee, \& Wiseman, 2015).

Yağ, tuz ve şeker açısından zengin işlenmiş besinlerin tüketimlerinin artması, dünya çapında obezite prevalansının yüksek olmasına katkıda bulunan önemli bir faktördür (Botelho, de Camargo, Dean, \& Fiates, 2019). Bireysel besin seçimleri biyolojik (hastalığa genetik yatkınlık, besine karşı hassasiyet veya alerjiler), psikolojik (tercihler, kişilik ve sağlıklı beslenmeye karş1 ilgi) ve sosyal (cinsiyet rolleri) olmak üzere kişisel ve çevresel faktörlerden etkilenmektedir (Papier, Ahmed, Lee, \& Wiseman, 2015). Besin endüstrisinin ürünleri satmak ve besin seçimlerini etkilemek için kullandığ 1 stratejiler nedeniyle, bireyler sağlıklı besin seçimleri konusunda bilgili olsalar bile bu bilgiler her zaman sağlıklı alışveriş alışkanlıklarına dönüşemez (Botelho, de Camargo, Dean, \& Fiates, 2019).

İşlenmiş besinler, tüm yaş grupları için giderek daha kolay erişilebilir hale gelen işlenmiş besin ve içecek tüketiminin artması, obezite ve kronik hastalıkların artan prevalansına katkıda bulunan faktörlerden biri olarak kabul edilmektedir (Rico-
Campà ve ark., 2019). Duygusal yemenin stresin etkilerini hafifletme arzusundan kaynaklandığ 1 ve stresin k1smen hipotalamik-hipofiz-adrenal (HPA) ekseni tarafindan düzenlendiği bilinmektedir (Jacques ve ark., 2019). Şekerli besinlerin tüketimi sonucunda HPA ekseni aktivitesinin azaldığ 1 gösterilmiştir. Tüketimi takiben, stres duygularını azaltmak için hormonlar salınır, bu da şekerli yiyeceklere olan isteği daha da artırarak duygusal yeme alışkanlıklarını sürdürmektedir (Jacques ve ark., 2019).

Üniversite eğitimine başlama birey için önemli bir yaşam değişikliği getirmesi açısından stresli bir deneyim olabilir. Üniversite öğrencileri, günlük yaşamlarında birçok stres etkeni ile karşı karşıyadır. Yeni sosyal ilişkiler, akran rekabeti, zaman yönetiminde eksiklikler, yüksek notlar alma isteği ve çabası öğrencilerde strese neden olabilecek veya onları ağırlaştırabilecek faktörlerden bazılarıdır (Papier, Ahmed, Lee, \& Wiseman, 2015). Stres, besin tercihlerini ve tüketimini değiştirebilecek biyolojik ve psikolojik değişikliklere neden olmaktadır (Zellner ve ark., 2006). Araştırmalar, stresli bireylerin besin seçimlerinin bulundukları ülke, etkilendikleri kültür, cinsiyetleri gibi faktörlere göre değiş̧ebileceğini göstermektedir (Mohamed, Mahfouz, \& Badr, 2020). Üniversiteye geçiş dönemi, gelecekteki sağl1k davranışlarının oluşturulması için çok önemlidir. $\mathrm{Bu}$ nedenle, stres ve sağlıklı beslenme davranışı arasında olumsuz bir ilişki, özellikle genç üniversite öğrencileri için endişe verici olmaktadır. Bu çalışmanın amacı, Ankara'da üniversite okuyan öğrencilerin sinav ve sinav olmayan dönemlerinde stres düzeylerini belirlemek ve stres durumlarının işlenmiş besinler, şeker ve fruktoz tüketimleri üzerine etkilerini değerlendirmektir.

\section{Gereç ve Yöntem}

$\mathrm{Bu}$ çalışma, Hacettepe Üniversitesi Girişimsel Olmayan Klinik Araştırmalar Etik Kurul tarafından etik açıdan uygun bulunmuştur (GO 21/650).

Çalışma Dizaynı: $\mathrm{Bu}$ çalışmada, çalışmanın kriterlerine uyan ve çalışmaya katılmayı kabul eden bireylere dört bölümden oluşan 


\section{Üniversite Öğrencilerinin Stres Durumları ile Fruktoz ve İşlenmiş Besin Tüketimi Arasındaki İlişki}

sosyodemografik bilgi, işlenmiş besin tüketim siklığı, fruktoz tüketim sıklığı, algılanan stres ölçeğini içeren anket uygulanmıștır. Tüm veriler öğrencilerden final sinavi dönemi ve sinav olmayan bir dönem olmak üzere iki kez toplanmıştır. Final haftası akademik yılın en stresli dönemi olduğu için tercih edilmiş̧tir.

Örneklem: Örneklem büyüklüğü $\alpha=0.05$ ve $85 \%$ 'lik bir güçle NCSS-PASS programında minimum 200 birey olarak hesaplanmıştır. Çalışmaya dâhil olma kriterleri;

- Ankara'da üniversite okumak

- 18-25 yaş arasında olmak

Hariç tutulma kriterleri,

- Menstrüasyon dönemi içinde olmak

- Herhangi bir kronik hastalığı, sendrom ve/veya sistemik hastalığı olanlar,

- İştahı etkileyen ilaç (antidepresan, metformin vb.) kullananlar,

- Gebe ve emzikli kadınlar,

- Psikiyatrik bir hastalığı olanlar ve/veya yeme davranışı tedavisi alanlar,

- Beslenme ve Diyetetik Bölümünde okuyanlar

\section{Verilerin toplanması}

Algılanan Stres Ölçeği (ASÖ)

Algılanan Stres Ölçeği (ASÖ) Cohen ve arkadaşları tarafından geliştirilmiş (Cohen, Kamarck, \& Mermelstein, 1983) ve Türkçe adaptasyonu ve geçerlilik-güvenirlik çalışması Eskin ve arkadaşları (Eskin, Harlak, Demirkıran, \& Dereboy, 2013) tarafından yapılmıştır. Bireyin hayatında karşılaştığı birtakım durumlar karşısında ne derece stres algıladığını ölçmek için oluşturulan bu ölçek toplamda 14 maddeden oluşmaktadır. Her madde "Hiçbir zaman (0)" ve "Çok sık (4)" arasında değişen 5'li Likert tipi ölçek üzerinden değerlendirilmektedir. 0-56 arasında değişen ASÖ-14'ün puanı yükseldikçe bireyin algıladığ1 stresin arttığını göstermektedir.

\section{İşlenmiş Besin Tüketimi}

2009'da yayınlanan NOVA siniflandirmasi (Rico-Campà ve ark., 2019), besinleri endüstriyel besin işleme kapsamına ve amacına göre sinıflandırmaktadır. Besinler işlenmemiş, minimum düzeyde işlenmiş, işlenmiş mutfak malzemeleri, işlenmiş veya aşırı işlenmiş olarak siniflandırılmaktadır.

Kantitatif besin tüketim sıklığı anketinde (günde birkaç kez, günlük, haftada birkaç kez, ayda 1-4 kez ve asla) 21 besin maddesi işlenmiş veya aşırı işlenmiş olarak sınıflandırılmaktadır. Kek, kurabiyeler, tatlilar, alkolsüz içecekler, tuzlanmış, işlenmiş ve tütsülenmiş etler, sosisler, soslar, atıştırmalıklar, pizza, tuzlu ve kızarmış yiyecekler ve şekerli sütlü içecekler olmak üzere gruplara ayrılmıştır.

\section{Fruktoz Tüketim Sıklı̆̆ı}

Fruktoz tüketimi durumu, literatürde fruktoz içeriği belirlenmiş olan fruktozdan zengin besinler seçilerek, konu ile ilgili kaynaklardan elde edilen bilgiler doğrultusunda hazırlanan tüketim sıklığ 1 (her ögün, her gün, haftada 5-6 kez, haftada 3-4 kez, haftada 1-2 kez, 15 günde bir, ayda $1 \mathrm{kez}$, seyrek, hiç olmak üzere) ve miktarı sorgulanarak belirlenmiştir. Toplamda 51 besini içeren bu tüketim sıklığı anketi taze meyveler, kuru meyveler, sebzeler, içecekler, şeker ve tatlılar olmak üzere beş grup altında değerlendirilmiştir. Günlük fruktoz tüketim miktarları Türkiye için geliștirilen "Beslenme Bilgi Sistemleri" (BEBİS) programı aracılığı ile belirlenmiştir.

İstatistiksel Analiz: Tüm veriler IBM SPSS Versiyon 23.0 istatistiksel paket programı ile analiz edilmiştir. Her parametre için ortalama, standart sapma ve standart hatayı içeren tanımlayıcı istatistikler hesaplanmıştır. Tekrarlı ölçümler, normal dağ 11 lım gösteren değişkenler için bağımlı gruplar Student-t testi kullanılarak karșilaștırılmıştır. Normal dağılım göstermeyen değișkenlerin için gruplar arası farklılıklar Wilcoxon testi ile saptanmıştır. $\mathrm{p}<0.05$ istatistiksel olarak anlamlı sonuçlar şeklinde değerlendirilmiştir.

\section{Bulgular ve Tartışma}

Öğrencilerin genel özellikleri ve beslenme alışkanlıklarına yönelik bilgiler Tablo 1'de verilmiştir. Çalışmaya 93 erkek 132 kadın olmak üzere toplamda 225 öğrenci katılmıştır. Öğrencilerin yaş ortalaması $21.2 \pm 1.46$ yıldır. Çalışmaya katılan bireylerin 2.7\%'si hazırlık, 9,8\%'i birinci sinif, 25.8\%'i ikinci sinif, 32.4\%'ü üçüncü sınıf, 29.3'\%ü ise dördüncü 


\section{Üniversite Öğrencilerinin Stres Durumları ile Fruktoz ve İşlenmiş Besin Tüketimi Arasındaki İlişki}

sınıf öğrencisidir. Katılımciların 30.7\%'si ana ögünleri her zaman, 41.8\%'i bazen atlarken; 27.5\%’i ana ögünleri atlamamaktadır. Ögün atlama nedeni olarak da çoğunluğun (53\%) vakit bulamama nedeniyle ana öğünleri atladığı görülmüştür.

Tablo 1. Öğrencilerin genel özellikleri ve beslenme alışkanlıkları

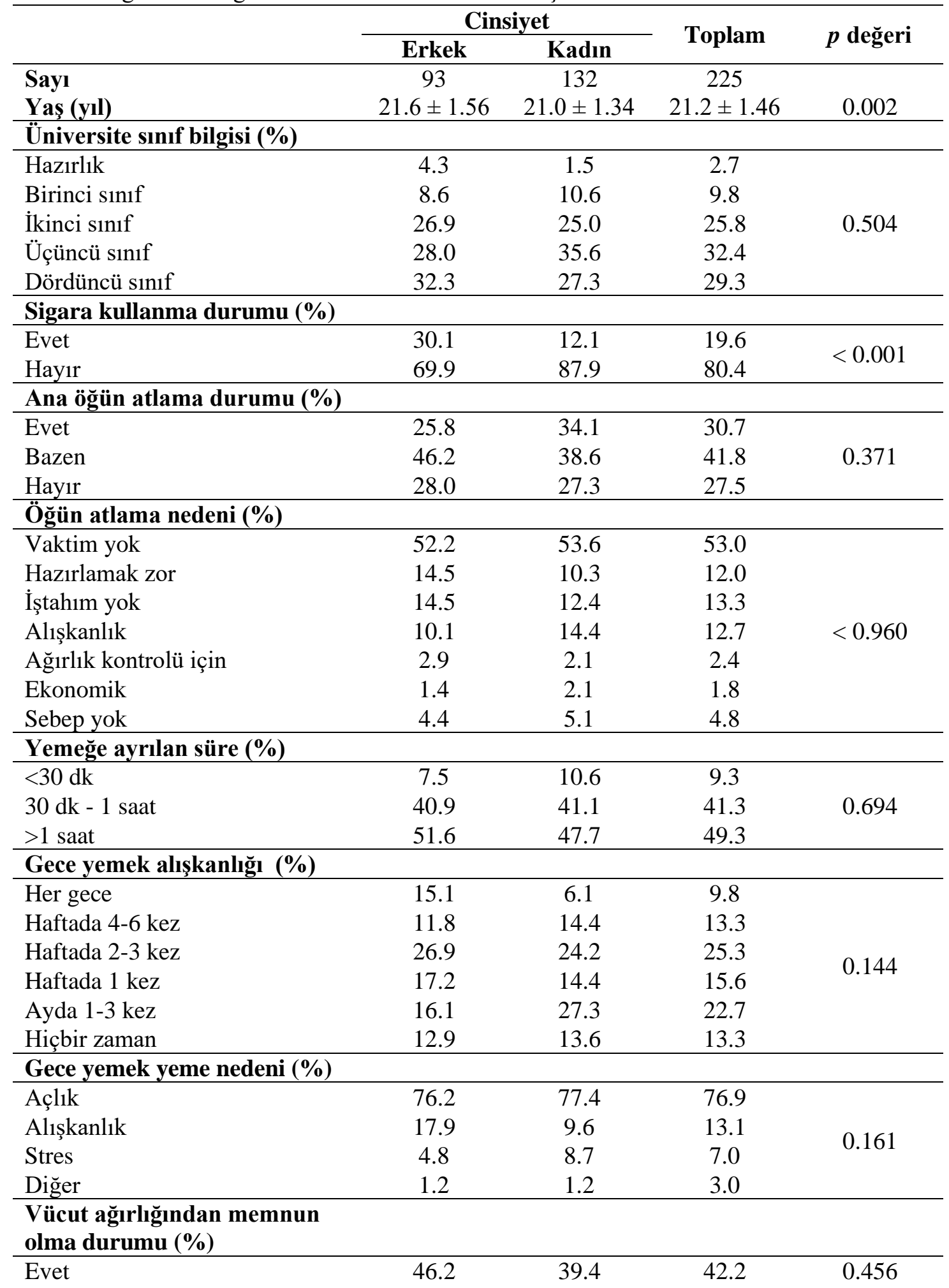




\section{Üniversite Öğrencilerinin Stres Durumları ile Fruktoz ve İşlenmiş Besin Tüketimi Arasındaki İlişki}

\begin{tabular}{lccc} 
Hayır & 37.6 & 38.6 & 38.2 \\
Kararsiz & 16.1 & 22 & 19.6 \\
\hline
\end{tabular}

Tablo 2. Öğrencilerin sınav öncesi ve sınav dönemlerine ait stres skorları (Ort $\pm \mathrm{SS})$

\begin{tabular}{lllll}
\hline & & Sinav öncesi dönem & Sınav dönemi & $p$ değeri \\
\cline { 3 - 5 } Algılanan stres & Erkek & $43.2 \pm 4.22$ & $44.3 \pm 4.69$ & 0.056 \\
ölçeği skoru & Kadın & $44.2 \pm 4.54$ & $45.8 \pm 4.92$ & 0.002 \\
\cline { 2 - 5 } & Toplam & $43.8 \pm 4.43$ & $45.2 \pm 4.87$ & $<0.001$ \\
\hline
\end{tabular}

Hem erkek hem de kız öğrencilerin sınav dönemlerinde stres düzeylerinin sinav olmayan döneme göre artış gösterdiği saptanmıştır $(\mathrm{p}<0.001) \quad($ Tablo 2). Akademik stres, akademik ortam, sınav kaygısı ve zor bilişsel görevleri yerine getirme ile iliş̧kili stresi ifade etmektedir. Lisans düzeyindeki öğrencilerde stres ve besin seçimi arasındaki ilişkiyi inceleyen bu çalışmada bu örneklem grubu için önemli bir stres faktörü olduğu için akademik stres seçilmiştir. Psikososyal stresin beyindeki iştah kontrolü mekanizmaları üzerindeki etkilerinin incelendiği bir çalışmada üniversite öğrencilerinde final sinavi döneminde algilanan stres seviyelerinin arttığ rapor edilmiştir (Neseliler ve ark., 2017). Benzer şekilde Michels ve arkadaşları (Michels, Man, Vinck, \& Verbeyst, 2020) üniversite öğrencilerinin sinav dönemlerinde algılanan stres düzeylerinin arttı̆̆ını, diyet kalitelerinin azaldığını, sebze ve meyve tüketimlerinin azalarak fast-food tüketimlerinin önemli ölçüde arttığını bildirmişlerdir. Algılanan stresin artması, sebze ve meyve gibi besleyici değeri yüksek sağl1klı besinlerin tüketimini azaltarak ve şeker içeriği yüksek, enerji yoğun, besin değeri düşük sağlıksız besinlerin tüketimini artırarak üniversite öğrencilerinin besin seçimleri üzerinde olumsuz etkilere neden olabilmektedir. Üniversite öğrencilerinin stres seviyelerinin sinav dönemlerinde yüksek olduğu ve bu durumun diyet kalitelerinde azalmaya neden olduğu gösterilmiştir (Harris, Pomeranz, Lobstein, \& Brownell, 2009). Koreli lise ögrencileri arasında yapılan bir çalışmada (Kim, Yang, Kim, \& Lim, 2013) akademik stresi yüksek olan öğrencilerin şeker içeriği yüksek besin tüketim sıklığı ve tüketilen şeker miktarının akademik stres düzeyi düşük öğrencilere göre daha yüksek olduğu gösterilmiştir. Kadın üniversite öğrencileri üzerinde yapılan bir çalışmada (Emond ve ark., 2016) ise akademik stresin toplam enerji alımında artışa neden olduğu ve özellikle karbonhidrat ve şeker tüketimlerini arttırdığ1 bulunmuştur. Stres durumunda tatlı tat algısı zayıfladığı için telafi mekanizması ile tatlı besinlerin seçilmesi ve tüketimlerinin artırılması söz konusu olabilmektedir (Al'Absi, Nakajima, Hooker, Wittmers, \& Cragin, 2012). Stres altındaki kadınlarda lezzetli atıștırmalık yiyeceklere yönelme davranışı gösterilmiştir (Wallis \& Hetherington, 2009). Algilanan stresin artmas1, üniversite öğrencilerinde sağlıksız beslenme alıșkanlıklarının başlamasına ve bu alışkanlıkların sürdürülmesine yol açabilmektedir. Üniversite öğrencileri ve beslenme alışkanlıkları ile ilgili olarak farklı ülkelerde yapılan çalışmalarda genç yetişkinlerin stresli durumlar karşısında aşırı yeme ve sağliksız besinler tüketme eğiliminde oldukları bildirilmiştir (Adams \& Rini, 2007; Carter, Elzubeir, Abdulrazzaq, Revel, \& Townsend, 2003; Macht, Haupt, \& Ellgring, 2005). Algılanan stresin artması iştah artışı, tıkınırcasına yeme davranışı ve daha fazla enerji tüketimi ile ilişkilendirilmiştir (Crowther, Sanftner, Bonifazi, \& Shepherd, 2001; Freeman \& Gil, 2004; Tuschen-Caffier \& Vögele, 1999). Aynı zamanda artan algılanan stres düzeyi ile şekerli besin, hızlı yemekler ve atıştırmalık besinlerin tüketimlerinin artması ve ana öğün düzenindeki et, balık ve sebze yemekleri ve taze meyve tüketimlerinin azalması ile ilişkili bulunmuştur (Kandiah, Yake, Jones, \& Meyer, 2006; Oliver \& Wardle, 1999). Özellikle sinav döneminde algılanan stresin artması sonucu besin değeri yüksek olan sebze-meyve gibi sağlıklı besin gruplarının tüketimlerinin azalması ve enerji içeriği yüksek ancak besin değeri düşük olan işlenmiş besinler ve şekerli besinlerin 


\section{Üniversite Öğrencilerinin Stres Durumları ile Fruktoz ve İşlenmiş Besin Tüketimi Arasındaki İlişki}

tüketimlerini artırarak öğrencilerin besin seçimleri üzerinde olumsuz etkilere sahip olabilmektedir (Harris, Pomeranz, Lobstein, \& Brownell, 2009). Üniversite birinci sinif öğrencileri arasında yapılan bir çalışmada
(Errisuriz, Pasch, \& Perry, 2016) algilanan stres düzeyi ile tuzlu paketlenmiş atıştırmalık, dondurulmuş besinler ve fast-food tüketimleri arasında pozitif ilişki bulunmuştur.

Tablo 3. Öğrencilerin sınav öncesi ve sınav sonrası dönemde günlük işlenmiş besin tüketim miktarları (g/gün) (Ort $\pm \mathrm{SS})$

\begin{tabular}{|c|c|c|c|c|c|c|}
\hline \multirow[b]{2}{*}{$\begin{array}{l}\text { İşlenmiş } \\
\text { Besinler }\end{array}$} & \multicolumn{3}{|c|}{ Erkek } & \multicolumn{3}{|c|}{ Kadın } \\
\hline & $\begin{array}{l}\text { Sinav öncesi } \\
\text { dönem }\end{array}$ & Sınav dönemi & $\begin{array}{l}p \\
\text { değeri }\end{array}$ & $\begin{array}{l}\text { Sinav } \\
\text { öncesi } \\
\text { dönem }\end{array}$ & $\begin{array}{l}\text { Sinav } \\
\text { dönemi }\end{array}$ & $\begin{array}{l}p \\
\text { değeri }\end{array}$ \\
\hline Salam & $4.4 \pm 13.36$ & $6.4 \pm 12.31$ & 0.01 & $1.3 \pm 4.34$ & $2.0 \pm 6.87$ & 0.54 \\
\hline Sucuk & $10.5 \pm 15.22$ & $12.7 \pm 19.46$ & 0.17 & $4.1 \pm 9.94$ & $3.6 \pm 6.62$ & 0.90 \\
\hline Sosis & $4.8 \pm 12.42$ & $5.1 \pm 9.89$ & 0.66 & $1.9 \pm 6.43$ & $3.3 \pm 11.27$ & 0.07 \\
\hline Pastırma & $0.6 \pm 2.93$ & $0.6 \pm 0.20$ & 0.225 & $0.01 \pm 0.13$ & $0.1 \pm 0.50$ & 0.09 \\
\hline $\begin{array}{l}\text { Dondurulmuş } \\
\text { Etler }\end{array}$ & $18.0 \pm 43.52$ & $35.6 \pm 88.23$ & $<0.001$ & $5.4 \pm 9.52$ & $8.0 \pm 15.58$ & 0.17 \\
\hline Krema & $0.3 \pm 1.46$ & $1.2 \pm 5.00$ & 0.02 & $0.5 \pm 1.61$ & $2.3 \pm 8.10$ & $<0.001$ \\
\hline Nugget & $3.9 \pm 11.35$ & $8.4 \pm 21.07$ & 0.01 & $1.9 \pm 7.27$ & $3.4 \pm 10.80$ & 0.02 \\
\hline $\begin{array}{l}\text { Soğan } \\
\text { halkaları }\end{array}$ & $1.7 \pm 6.29$ & $3.4 \pm 7.36$ & 0.009 & $1.4 \pm 4.81$ & $2.3 \pm 7.88$ & 0.004 \\
\hline $\begin{array}{l}\text { Hazır pastane } \\
\text { ürünleri }\end{array}$ & $31.6 \pm 39.60$ & $37.5 \pm 54.55$ & 0.64 & $19.5 \pm 23.2$ & $25.0 \pm 42.29$ & 0.43 \\
\hline Çikolata & $19.6 \pm 22.26$ & $32.7 \pm 36.55$ & $<0.001$ & $23.5 \pm 27.51$ & $41.4 \pm 41.97$ & $<0.001$ \\
\hline Şekerleme & $3.3 \pm 12.45$ & $6.2 \pm 23.02$ & 0.03 & $2.4 \pm 10.43$ & $5.0 \pm 12.39$ & $<0.001$ \\
\hline Patates cipsi & $12.7 \pm 18.21$ & $28.8 \pm 36.66$ & $<0.001$ & $12.0 \pm 23.23$ & $17.3 \pm 27.18$ & 0.01 \\
\hline $\begin{array}{l}\text { Hazır } \\
\text { Çorbalar }\end{array}$ & $4.7 \pm 14.37$ & $15.2 \pm 41.81$ & 0.003 & $3.2 \pm 18.10$ & $6.4 \pm 30.55$ & 0.11 \\
\hline Hazır Soslar & $2.0 \pm 3.97$ & $3.8 \pm 10.15$ & 0.73 & $1.1 \pm 2.68$ & $1.4 \pm 3.72$ & 0.76 \\
\hline Pizza & $13.9 \pm 24.75$ & $24.4 \pm 37.13$ & $<0.001$ & $6.0 \pm 19.23$ & $10.3 \pm 27.04$ & 0.02 \\
\hline $\begin{array}{l}\text { Kahvaltılik } \\
\text { Gevrek }\end{array}$ & $0.98 \pm 3.60$ & $7.98 \pm 52.67$ & 0.02 & $1.45 \pm 5.25$ & $3.39 \pm 12.09$ & 0.005 \\
\hline Milkshake & $2.3 \pm 8.68$ & $11.0 \pm 35.92$ & 0.005 & $0.8 \pm 4.58$ & $4.0 \pm 22.49$ & 0.005 \\
\hline $\begin{array}{l}\text { Gazlı } \\
\text { İçecekler }\end{array}$ & $53.9 \pm 105.92$ & $124.2 \pm 269.83$ & $<0.001$ & $18.1 \pm 36.25$ & $36.1 \pm 77.62$ & 0.003 \\
\hline
\end{tabular}

$\mathrm{Bu}$ çalışmada öğrencilerin cinsiyetlerine göre sınav öncesi ve sınav döneminde tükettikleri işlenmiş besinlerin ortalama miktarları Tablo 3 'de gösterilmektedir. Erkek öğrencilerin salam, dondurulmuş etler, krema, nugget, soğan halkaları, çikolata, şekerleme, patates cipsi, hazır çorba, pizza, kahvaltılık gevrek, milkshake ve gazlı içecek tüketimleri, sınav öncesi döneme göre sınav döneminde anlamlı artış göstermiştir $(p<0.05)$. Kadın öğrencilerde ise sinav döneminde krema, nugget, soğan halkaları, çikolata, şekerleme, patates cipsi, pizza, kahvaltılık gevrek, milkshake ve gazlı içecek tüketimlerinin istatistiksel olarak anlamlı artış gösterdiği bulunmuştur $(\mathrm{p}<0.05)$. Bu çalışma sonuçlarına benzer olarak üç Avrupa ülkesinde (Almanya, Polonya ve Bulgaristan) yürütülen bir çalışmada birinci sınıf üniversite öğrencilerinde stres ile işlenmiş besin tüketimleri arasında pozitif bir ilişki bulunmuştur (Mikolajczyk, El Ansari, \& Maxwell, 2009). Özellikle üniversite öğrencilerinin paketlenmiş ve işlenmiş besinlere talebi oldukça fazladır. $\mathrm{Bu}$ durum, işlenmiş besinlerin ișlenmemiș besinlere kıyasla hazırlanmasının daha kolay ve hızlı olması ile ilişkilendirilebilir. $\mathrm{Bu}$ durumun altında yatan 


\section{Üniversite Öğrencilerinin Stres Durumları ile Fruktoz ve İşlenmiş Besin Tüketimi Arasındaki İlişki}

sebebin stres altındayken hizlı ve kolay bir şekilde enerji kaynağ 1 elde etme davranışına yönelmenin olabileceği düșünülmektedir (Errisuriz, Pasch, \& Perry, 2016). Bu hipotezi destekler şekilde Kanada'da üniversite öğrencilerinde yapılan bir çalışmada besin seçiminde en önemli belirleyicinin kolaylık olduğu bulunmuştur (Marquis, 2005). Özellikle ultra işlenmiş besinler hazırlama ve pişirme aşamalarını gerektirmeden tüketilmek üzere tasarlanmaktadır. $\mathrm{Bu}$ besinler genellikle atıştırmalıklar, içecekler veya tüketime hazır yemekler şeklinde piyasaya sunulmaktadır. Son yıllarda besin ulaşılabilirliğinin giderek daha da kolay olmasının da stres ve besin seçimi arasındaki ilişkiye katkıda bulunan başka bir faktör olabileceği düşünülmektedir (Privitera, Misenheimer, \& Doraiswamy, 2013).

Tablo 4. Öğrencilerin sınav öncesi ve sınav döneminde fruktoz içeren besinlerin günlük tüketim miktarları ve günlük toplam şeker ve fruktoz alımları (g/gün) (Ort \pm SS)

\begin{tabular}{|c|c|c|c|c|c|c|}
\hline & \multicolumn{3}{|c|}{ Erkek } & \multicolumn{3}{|c|}{ Kadın } \\
\hline $\begin{array}{l}\text { Tüketim } \\
\text { miktarları } \\
\text { (g/gün) }\end{array}$ & $\begin{array}{l}\text { Sinav öncesi } \\
\text { dönem }\end{array}$ & Sınav dönemi & $\begin{array}{l}p \\
\text { değeri }\end{array}$ & $\begin{array}{l}\text { Sinav öncesi } \\
\text { dönem }\end{array}$ & Sınav dönemi & $\begin{array}{l}p \\
\text { değeri }\end{array}$ \\
\hline Taze meyveler & $102.8 \pm 93.31$ & $\begin{array}{l}135.4 \pm \\
118.72\end{array}$ & 0.015 & $121.5 \pm 94.19$ & $\begin{array}{l}179.8 \pm \\
227.72\end{array}$ & 0.003 \\
\hline Kuru meyveler & $2.0 \pm 5.21$ & $9.1 \pm 17.51$ & $<0.001$ & $6.1 \pm 11.91$ & $12.4 \pm 22.17$ & $<0.001$ \\
\hline Sebzeler & $45.3 \pm 53.85$ & $54.6 \pm 69.64$ & 0.371 & $36.2 \pm 43.75$ & $44.8 \pm 59.94$ & 0.260 \\
\hline $\begin{array}{l}\text { Şeker eklenmiş } \\
\text { hazır içecekler }\end{array}$ & $\begin{array}{l}321.5 \pm \\
316.38\end{array}$ & $\begin{array}{l}557.7 \pm \\
597.43\end{array}$ & $<0.001$ & $\begin{array}{l}166.7 \pm \\
221.27\end{array}$ & $\begin{array}{l}266.2 \pm \\
411.97\end{array}$ & $<0.001$ \\
\hline $\begin{array}{l}\text { Şeker eklenmiş } \\
\text { hazır yiyecekler }\end{array}$ & $125.1 \pm 97.50$ & $\begin{array}{l}202.5 \pm \\
181.74 \\
\end{array}$ & $<0.001$ & $\begin{array}{l}106.9 \pm \\
106.39 \\
\end{array}$ & $\begin{array}{l}180.7 \pm \\
257.16 \\
\end{array}$ & $<0.001$ \\
\hline Șeker (sükroz) & & & & & & \\
\hline $\begin{array}{l}\text { Doğal } \\
\text { kaynaklardan }\end{array}$ & $3.4 \pm 2.04$ & $6.9 \pm 7.13$ & 0.004 & $5.5 \pm 4.33$ & $9.4 \pm 10.89$ & 0.008 \\
\hline İşlenmiş/eklenmiş & $69.9 \pm 60.81$ & $121.8 \pm 90.05$ & $<0.001$ & $53.8 \pm 49.92$ & $86.1 \pm 90.07$ & $<0.001$ \\
\hline $\begin{array}{l}\text { Toplam şeker } \\
\text { tüketimi }\end{array}$ & $73.3 \pm 62.24$ & $128.7 \pm 97.81$ & $<0.001$ & $59.3 \pm 52.78$ & $95.5 \pm 109.05$ & $<0.001$ \\
\hline Fruktoz & & & & & & \\
\hline $\begin{array}{l}\text { Doğal } \\
\text { kaynaklardan }\end{array}$ & $6.8 \pm 4.46$ & $10.4 \pm 7.13$ & 0.006 & $8.7 \pm 7.33$ & $13.1 \pm 10.89$ & 0.001 \\
\hline İşlenmiş/eklenmiş & $21.2 \pm 18.89$ & $36.1 \pm 20.72$ & $<0.001$ & $12.9 \pm 9.18$ & $21.1 \pm 14.56$ & $<0.001$ \\
\hline $\begin{array}{l}\text { Toplam fruktoz } \\
\text { tüketimi }\end{array}$ & $28.0 \pm 17.52$ & $46.5 \pm 23.06$ & $<0.001$ & $21.6 \pm 16.93$ & $34.2 \pm 25.83$ & $<0.001$ \\
\hline
\end{tabular}

Tablo 4, sinav öncesi ve sinav döneminde öğrencilerin cinsiyetlerine göre diyette fruktoz kaynağı olan besinlerin ortalama günlük tüketim miktarlarını ve ortalama günlük şeker ve fruktoz tüketimlerini göstermektedir. Fruktoz kaynaklarına göre besinler gruplandırıldığında hem erkek hem de kadın öğrencilerin taze meyve ve kuru meyve tüketimleri sınav öncesi döneme kıyasla sınav döneminde anlamlı artış gösterirken $(p<0.05)$, sebze tüketimleri sinav öncesi dönemle benzerlik göstermiştir ( $\mathrm{p}>0.05)$. Bunun yanı sıra şeker eklenmiş paketlenmiş içecek ve yiyecek tüketimleri sınav döneminde anlamlı artış göstermiştir $\quad(\mathrm{p}<0.001)$. Katılımciların sınav öncesi ve sınav döneminde cinsiyetlerine göre günlük ortalama şeker ve fruktoz tüketim miktarları incelendiğinde, her iki cinsiyette de sinav döneminde toplam şeker ve fruktoz alımının arttığı gözlenmiştir $(\mathrm{p}<0.001)$. Katılımcıların sınav döneminde şeker ve fruktoz tüketiminin artması, stres durumunda şekerli besinlere yönelimin $\operatorname{arttığ} 1$ hipotezini desteklemektedir. 


\section{Üniversite Öğrencilerinin Stres Durumları ile Fruktoz ve İşlenmiş Besin Tüketimi Arasındaki İlişki}

Fruktoz, meyve ve sebzelerde doğal olarak bulunan basit șekerlerden biridir. Ancak besinlerdeki fruktozun çoğunluğu yiyecek ve içecek üretiminde yaygın olarak kullanılan sükroz ve yüksek fruktozlu mısır şurubu olmak üzere iki kaynaktan gelmektedir. Yeterli ve dengeli beslenmede sebze ve meyve tüketiminin önemi bilinmektedir. Türkiye Beslenme Rehberinde (TÜBER) günde en az 5 porsiyon (400 g/gün) sebze ve meyve tüketimi vurgulanmaktadır. Yiyeceklerin doğal yapısında bulunan şeker dışında, üretim aşamasında eklenmiş şekerler ve sükrozun toplam günlük alım miktarı, toplam alınan günlük enerjinin 10\%'unu geçmemelidir (TÜBER, 2015). Disakkarit olan sükroz, $50 \%$ fruktoz ve $50 \%$ glikozdan oluşmaktadır. Yüksek fruktozlu mısır şurubu ise $55 \%$ fruktoz, $42 \%$ glikoz ve $3 \%$ oligosakkaritlerden oluşmaktadır. Yüksek fruktozlu misır şurubunun fruktoz içeriğinin sükrozdan daha yüksek olması nedeniyle yüksek fruktozlu mısır şurubu ile tatlandırılmış besinler sükroz ile tatlandırılmış besinlere göre diyette daha fazla fruktoz sağlamaktadır (Melanson ve ark., 2007; Patterson, Yee, Wahjudi, Mao, \& Lee, 2018; Taş, 2020). Yüksek fruktozlu mısır şurubu fiziksel ve fonksiyonel özelliklerinden dolayı şeker eklenmiş içecekler, kolalı içecekler, pastane ürünleri, sütlü tatlılar ve dondurma gibi süt ürünleri, kahvaltılık gevrekler, hazır soslar, hazır çorbalar ve işlenmiş besinlerde şeker ikamesi olarak kullanılmaktadır (Khorshidian ve ark., 2021). Düşük maliyeti, tatlılık oranının nispeten yüksek oluşu, yüksek hidrasyon özelliği ve sükrozdan daha iyi doku, renk ve kıvam oluşturması nedeniyle besin endüstrisinde yaygin olarak tercih edilmektedir (White \& Nicklas, 2016; Zargaraan, Kamaliroosta, Yaghoubi, \& Mirmoghtadaie, 2016). Bu sebeple yüksek fruktozlu mısır şurubunun tüketimi dünya çapında önemli ölçüde artmıştır (Taş, 2020). Ancak yüksek fruktoz alımı ile obezite ve metabolik sendrom gibi olumsuz sağlik etkileri arasında doğrudan bir ilişki olabileceği bildirilmektedir (White, 2014).

Her ikisi de monosakkarit olan fruktoz ve glikoz, farklı sindirim ve emilim süreçleri göstermektedir. Sükroz bağırsağa girerken disakkaridaz enzimi ile parçalanır ve yapısındaki glikoz sodyuma bağımlı yardımcı taşıyıcı sistemi tarafindan emilir. Fruktoz ise sodyuma bağımlı olmayan bir GLUT-5 taşıyıcısı tarafindan emilir. Emilen glikoz ve fruktoz portal dolaşıma girer ve karaciğere taşınır. Karaciğere giren fruktoz, glikoza dönüşebilir veya kan dolaşımına geçebilir (White, 2009). Öte yandan, büyük miktarlarda fruktoz alımı ile hepatik lipogenez artmaktadır (Bray, Nielsen, \& Popkin, 2004). Glikozun hücrelere taşınması çoğu dokuda insüline bağımlıdır. İnsülin reseptörlerinin aktivasyonu sonucu hücre yüzeyindeki glikoz taşıyıcılarının yoğunluğu artar ve glikozun hücrelere girişi kolaylaşır. Buna karşılık, fruktoz GLUT5 taşıyıcısı ile hücreye taşınır ve bu transport işlemi insüline bağımlı değildir (Khorshidian ve ark., 2021). Bu sebeple fruktozun besin alımını düzenleyici mekanizmaları atlayarak lipogenezi desteklediği düşünülmektedir (Khorshidian ve ark., 2021).

\section{Sonuç}

Akademik stresin, şekerli ve enerji yoğun besinlerin tercih edilmesi de dahil olmak üzere sağlıksız beslenme alışkanlıkları ile ilişkili olduğu açıktır. İșlenmiş besinlerin, şeker ve fruktozun yüksek tüketimi obezite, diyabet, metabolik sendrom ve kardiyovasküler hastalıklar gibi pek çok hastalıkla ilişkilendirilmektedir. Bu çalışmada üniversite öğrencilerinin sınav döneminde işlenmiş besin tüketimi ve işlenmiş besin ve içeceklerden gelen şeker ve fruktoz tüketimlerinin arttı̆̆ gözlenmiştir. $\mathrm{Bu}$ durumun sağlik üzerindeki etkileri nedeniyle bireylerin sağlıklı besin alternatifleri ve sağlıklı beslenme alışkanlıkları hakkında eğitiminin gerekliliği ortaya çıkmaktadır. Sebze ve meyveler gibi kaynaklardan gelen fruktozun doğal yapıda bulunması ve bu besinlerin vitamin, mineral ve posa yönünden zengin olmaları açısından sağlıklı beslenme kapsamında önerilmektedir. Ancak ișlenmiș besin ve içecekler gibi doğal olmayan kaynaklardan sağlanan fruktoz ve basit şeker tüketimleri sinırlandırılmalıdır. $\mathrm{Bu}$ çalışmanın bulguları, beslenme uzmanlarına, öğrencilerin sağlığını iyileştirmek için strese bağlı besin tüketimine yönelik müdahaleler geliştirmelerinde yardımcı olmak için kullanılabilir. 


\section{Üniversite Öğrencilerinin Stres Durumları ile Fruktoz ve İşlenmiş Besin Tüketimi Arasındaki İlişki}

\section{Kaynaklar}

Adams, T., \& Rini, A. (2007). Predicting 1-year change in body mass index among college students. Journal of American College Health, 55(6), 361-366.

Al'Absi, M., Nakajima, M., Hooker, S., Wittmers, L., \& Cragin, T. (2012). Exposure to acute stress is associated with attenuated sweet taste. Psychophysiology, 49(1), 96-103.

Beslenme Bilgi Sistemi - BeBiS, Versiyon 8.2; 2019, İstanbul.

Botelho, A. M., de Camargo, A. M., Dean, M., \& Fiates, G. M. (2019). Effect of a health reminder on consumers' selection of ultra-processed foods in a supermarket. Food Quality and Preference, 71, 431-437.

Bray, G. A., Nielsen, S. J., \& Popkin, B. M. (2004). Consumption of high-fructose corn syrup in beverages may play a role in the epidemic of obesity. The American journal of clinical nutrition, 79(4), 537-543.

Carter, A. O., Elzubeir, M., Abdulrazzaq, Y. M., Revel, A. D., \& Townsend, A. (2003). Health and lifestyle needs assessment of medical students in the United Arab Emirates. Medical Teacher, 25(5), 492496.

Cartwright, M., Wardle, J., Steggles, N., Simon, A. E., Croker, H., Jarvis, M. J. (2003). Stress and dietary practices in adolescents. Health Psychology, 22(4), 362-369.

Cohen, S., Kamarck, T., Mermelstein, S. (1983). A global measure of perceived stress. Journal of Health and Social Behavior, 24(4):385-396.

Crowther, J. H., Sanftner, J., Bonifazi, D. Z., \& Shepherd, K. L. (2001). The role of daily hassles in binge eating. International Journal of Eating Disorders, 29(4), 449454.

Emond, M., Ten Eycke, K., Kosmerly, S., Robinson, A. L., Stillar, A., \& Van Blyderveen, S. (2016). The effect of academic stress and attachment stress on stress-eaters and stress-undereaters. Appetite, 100, 210-215.
Errisuriz, V. L., Pasch, K. E., \& Perry, C. L. (2016). Perceived stress and dietary choices: The moderating role of stress management. Eating behaviors, 22, 211216.

Eskin, M., Harlak, H., Demirkıran, F., \& Dereboy, Ç. (2013). Algilanan stres ölçeğinin Türkçeye uyarlanmasi: güvenirlik ve geçerlik analizi. In New/Yeni Symposium Journal (Vol. 51, pp. 132-140).

Freeman, L. M. Y., \& Gil, K. M. (2004). Daily stress, coping, and dietary restraint in binge eating. International Journal of Eating Disorders, 36(2), 204-212.

Harris, J. L., Pomeranz, J. L., Lobstein, T., \& Brownell, K. D. (2009). A crisis in the marketplace: how food marketing contributes to childhood obesity and what can be done. Annual review of public health, 30, 211-225.

Jacques, A., Chaaya, N., Beecher, K., Ali, S. A., Belmer, A., \& Bartlett, S. (2019). The impact of sugar consumption on stress driven, emotional and addictive behaviors. Neuroscience \& Biobehavioral Reviews, 103, 178-199.

Kandiah, J., Yake, M., Jones, J., \& Meyer, M. (2006). Stress influences appetite and comfort food preferences in college women. Nutrition Research, 26(3), 118123.

Khorshidian, N., Shadnoush, M., Zabihzadeh Khajavi, M., Sohrabvandi, S., Yousefi, M., \& Mortazavian, A. M. (2021). Fructose and high fructose corn syrup: are they a two-edged sword? International Journal of Food Sciences and Nutrition, 72(5), 592-614.

Kim, Y., Yang, H. Y., Kim, A.-J., \& Lim, Y. (2013). Academic stress levels were positively associated with sweet food consumption among Korean highschool students. Nutrition, 29(1), 213218.

Macht, M., Haupt, C., \& Ellgring, H. (2005). The perceived function of eating is changed during examination stress: a field study. Eating behaviors, 6(2), 109-112. 


\section{Üniversite Öğrencilerinin Stres Durumları ile Fruktoz ve İşlenmiş Besin Tüketimi Arasındaki İlişki}

Melanson, K. J., Zukley, L., Lowndes, J., Nguyen, V., Angelopoulos, T. J., \& Rippe, J. M. (2007). Effects of highfructose corn syrup and sucrose consumption on circulating glucose, insulin, leptin, and ghrelin and on appetite in normal-weight women. Nutrition, 23(2), 103-112.

Michels, N., Man, T., Vinck, B., \& Verbeyst, L. (2020). Dietary changes and its psychosocial moderators during the university examination period. European journal of nutrition, 59(1), 273-286.

Mikolajczyk, R. T., El Ansari, W., \& Maxwell, A. E. (2009). Food consumption frequency and perceived stress and depressive symptoms among students in three European countries. Nutrition journal, 8(1), 1-8.

Mohamed, B. A., Mahfouz, M. S., \& Badr, M. F. (2020). Food selection under stress among undergraduate students in Riyadh, Saudi Arabia. Psychology research and behavior management, 13, 211.

Neseliler, S., Tannenbaum, B., Zacchia, M., Larcher, K., Coulter, K., Lamarche, M., Marliss, E. B., Pruessner, J., \& Dagher, A. (2017). Academic stress and personality interact to increase the neural response to high-calorie food cues. Appetite, 116, 306-314.

Oliver, G., \& Wardle, J. (1999). Perceived effects of stress on food choice. Physiology \& behavior, 66(3), 511-515.

Papier, K., Ahmed, F., Lee, P., \& Wiseman, J. (2015). Stress and dietary behaviour among first-year university students in Australia: sex differences. Nutrition, 31(2), 324-330.

Patterson, M. E., Yee, J. K., Wahjudi, P., Mao, C. S., \& Lee, W.-N. P. (2018). Acute metabolic responses to high fructose corn syrup ingestion in adolescents with overweight/obesity and diabetes. Journal of nutrition \& intermediary metabolism, 14, 1-7.

Privitera, G. J., Misenheimer, M. L., \& Doraiswamy, P. M. (2013). From weight loss to weight gain: appetite changes in major depressive disorder as a mirror into brain-environment interactions. Frontiers in psychology, 4, 873.

Pollard, T. M., Steptoe, A., Canaan, L., Davies, G. J., \& Wardle, J. (1995). Effects of academic examination stress on eating behavior and blood lipid levels. International Journal of Behavioral Medicine, 2(4), 299-320.

Rico-Campà, A., Martínez-González, M. A., Alvarez-Alvarez, I., de Deus Mendonça, R., de la Fuente-Arrillaga, C., GómezDonoso, C., \& Bes-Rastrollo, M. (2019). Association between consumption of ultra-processed foods and all cause mortality: SUN prospective cohort study. BMJ, 365:11949.

Taş, F. (2020). Knowledge attitudes and behaviors of adult individuals about high fructose corn syrup consumption; cross sectional survey study. Clinical Nutrition ESPEN, 40, 179-186.

Tuschen-Caffier, B., \& Vögele, C. (1999). Psychological and physiological reactivity to stress: An experimental study on bulimic patients, restrained eaters and controls. Psychotherapy and Psychosomatics, 68(6), 333-340.

Türkiye Beslenme Rehberi (TÜBER) 2015. T.C. Sağlık Bakanlığı Yayın No:1031. Ankara, 2016.

Unusan, N. (2006). Linkage between stress and fruit and vegetable intake among university students: an empirical analysis on Turkish students. Nutrition Research, 26(8), 385-390.

Wallis, D. J., \& Hetherington, M. M. (2009). Emotions and eating. Self-reported and experimentally induced changes in food intake under stress. Appetite, 52(2), 355362.

White, J. S. (2009). Misconceptions about highfructose corn syrup: is it uniquely responsible for obesity, reactive dicarbonyl compounds, and advanced glycation endproducts? The Journal of nutrition, 139(6), 1219S-1227S.

White, J. S. (2014). Sucrose, HFCS, and fructose: history, manufacture, 


\section{Üniversite Öğrencilerinin Stres Durumları ile Fruktoz ve İşlenmiş Besin Tüketimi Arasındaki İlişki}

composition, applications, and production. In Fructose, high fructose corn syrup, sucrose and health (pp. 1333): Springer.

White, J. S., \& Nicklas, T. A. (2016). Highfructose corn syrup use in beverages: composition, manufacturing, properties, consumption, and health effects. In Beverage impacts on health and nutrition (pp. 285-301): Springer.

Zargaraan, A., Kamaliroosta, L., Yaghoubi, A. S., \& Mirmoghtadaie, L. (2016). Effect of substitution of sugar by high fructose corn syrup on the physicochemical properties of bakery and dairy products: a review. Nutrition and Food Sciences Research, 3(4), 3-11.

Zellner, D. A., Loaiza, S., Gonzalez, Z., Pita, J., Morales, J., Pecora, D., Wolf, A. (2006). Food selection changes under stress. Physiology \& Behavior, 87(4), 789-793. 
Üniversite Öğrencilerinin Stres Durumları ile Fruktoz ve İşlenmiş Besin Tüketimi Arasındaki İlişki 